\title{
The Effectivity of Losartan Tablet for Decreasing Fibrotic Tissue Formation in Gastrocnemius Muscle Injury Grade I of Rabbits
}

\author{
Boby Harul Priono*, Hermawan Rasyid, Yoyos Ismiarto, Ahmad Ramdan \\ Resident of Orthopedic and Traumatology Department, Universitas Padjadjaran/Dr.Hasan Sadikin General Hospital Bandung
}

\begin{abstract}
Muscle injuries among athletes require a complete recovery to be able to function optimally as before. However, in spite of implementing the management with PRICE (Protection, Rest, Immobilization, Compression and Elevation), during the recovery processes, fibrotic tissue will be formed, which is an unwanted non-functional muscle. Losartan is a blood pressure-lowering drug which has the inhibitory effect of inhibitory effect of TGF- $\beta$ cytokines (fibrotic tissue regulators). TGF- $\beta$ is the key to fibrotic formation and differentiation. Losartan has an effect on decreasing the TGF- $\beta$ production and it may affect the fibrotic tissue. This research is conducted by an experimental comparative method on the rabbit as study objects. Based on Federer formula sampling, twenty samples totally occurred. The random sampling method is adopted for comparing fibrotic tissue in two different groups (control group and losartan group). Losartan is administered orally. There were significant differences in the proportion of fibrotic tissue between the sample groups. The losartan group showed that the level of fibrotic intensity, distribution, and $\mathrm{H}$-score was decreased compared to the control group. Moreover, the result of Mann Whitney statistic test, for determining the H-score for both groups, showed that $\mathrm{p}$ is less than $0.05(\mathrm{p}<0.05)$, which implies that this research is statistically significant. This research proves that giving Losartan tablets brings a significant impact in reducing the formation of muscle fibrosis in muscle injury grade 1 in gastrocnemius rabbits.
\end{abstract}

Keywords: fibrotic; h-score; losartan; muscle injury grade 1

*Correspondence

Email : bobyharulpriono@gmail.com

\section{INTRODUCTION}

Muscle injury grade 1 is a common injury which placed up to $90 \%$ among all of the muscle injury (Medicine, 2012). The standard treatment for this injury is PRICE (Protect, Rest, Ice, Compression, Elevation), yet the healing process produces fibrotic tissues, which increases the possibility of recurrences as the muscle becomes weaker and less flexible (Nugroho, 2016). In the last decade, the incidence of muscle injuries is increasing. Muscle injuries divided into two based on the mechanism, indirect and direct types. Direct type is if there no direct external trauma appear (Ekstrand, Askling, Magnusson, \& Mithoefer, 2013). There are either structural injuries due to longitudinal distraction that make tears the muscle tissue or without evidence of a tear (Ekstrand et al., 2013). The most common direct case is because compressive to the thigh that usually compresses the muscles structures. Different from indirect type, muscle fibers usually are not torn. Direct injuries, especially muscle contusion, are common in sports, usually in high body contact sports types, such as football, rugby, basketball, and others. This kind of injury makes pain and may interfere joint motion of the athletes after the healing process (Trojian, 2013). Fibrotic tissue usually occurred after muscle injuries, substitute the functional muscle fiber to suboptimal muscle function. It makes muscles group less flexible and high risk to recurrence, in some case makes chronic pain. Therefore, we develop the new treatment in the management of muscle injury use Losartan drugs, this is a pilot study to applied Losartan in athlete muscle injury. Losartan is anti-hypertension drugs that widely known as angiotensin II receptor blocker (ARB) type, effective to decrease blood pressure with minimum complication and can be used in all age groups. Also, effective to treat cardiomyopathy and chronic renal disease. These drugs causing directly vasodilation of periphery blood vessel, and by reducing secreting of aldosterone and vasopressin. Activation of receptor angiotensin II by angiotensin II make production of thrombospondin-I, this secreted glycoprotein have been shown to be the regulator of TGF- $\beta$ activation. Therefore, inhibition of ATII and subsequences decreasing of TSP-1 will block the TGF- $\beta$ activation (Cohn et al., 2007).

Recent research shows the effectiveness of blocking TGF- $\beta$ production for fibrotic problems using antifibrotic agents, such as Decorin, Relaxin, and Suramin have good results (Mann et al., 2011; Terada et al., 2013). In Indonesia, this kind of drugs is difficult to find, have an expensive price $(0,5-2 \mathrm{USD} /$ tablet $)$ and have a lot of complication (Yang et al., 2011). Other research showed that Losartan also possesses the capacity 
of decreasing the TGF- $\beta$ secretion over mice which have Duchenne Muscular Dystrophy (DMD) (Meinen et al., 2012; Pessina et al., 2014). TGF- $\beta$ is cytokine key to differentiate myoblast to become myofibroblast, decreasing this cytokine will increase myocyte (functional muscle cell) production.

\section{METHODS}

This research was conducted using the experimental comparative method on the animal as study objects. The random sampling method was adopted for comparing quality and quantity value of the formation of fibrotic tissue in two different groups with muscle injury grade I based on histologic sampling and calculate with $\mathrm{H}$-score. The experiment was conducted in the Laboratory of Medical Research Unit of our institution from April to May 2016.

For this experiment, the subjects were rabbits which met the inclusion criteria: adult male rabbit, New Zealand races, 7 months old, weight 1-1,5 kg. Drop out criteria were decided as infection, fracture, dead rabbit, and changes in animal behavior. Using Federer formula to specify the number of samples needed, it was found that the experiment was totally to have 20 rabbits. Each group have 10 samples of rabbit.

To begin with, the muscle trauma was created on each rabbit by employing a dropping mass technique, which utilizing $1 \mathrm{~kg}$ load that was dropped from 0,5 meter high on the rabbits' gastrocnemius muscle, then bandaged using circular casts. Shortly afterwards, the research subjects were divided into two groups, the first group is the control group and the second group is the losartan treatment rabbits group. Group 1 as a control group was not administered losartan, while group 2 as

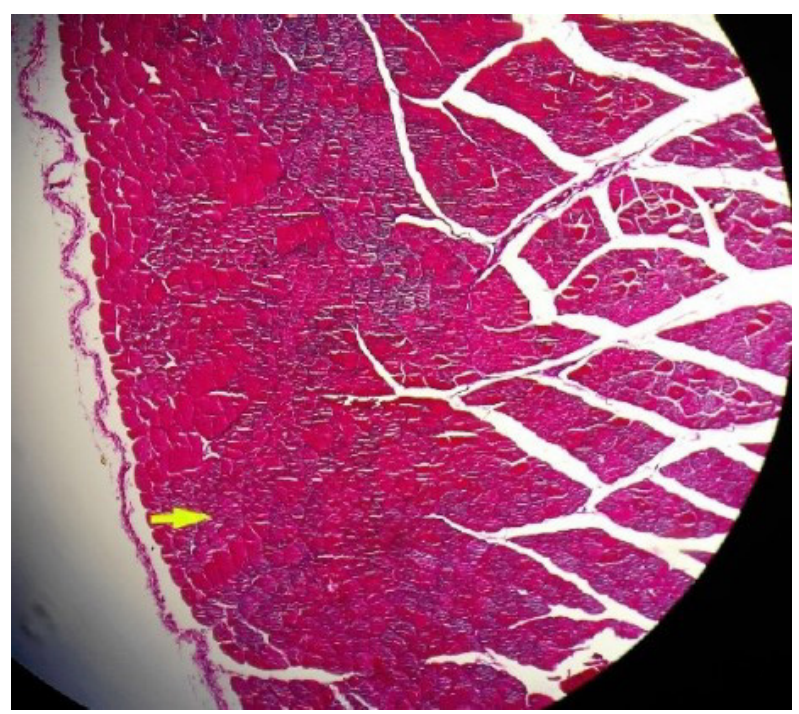

Figure 1. Muscles without fibrotic area

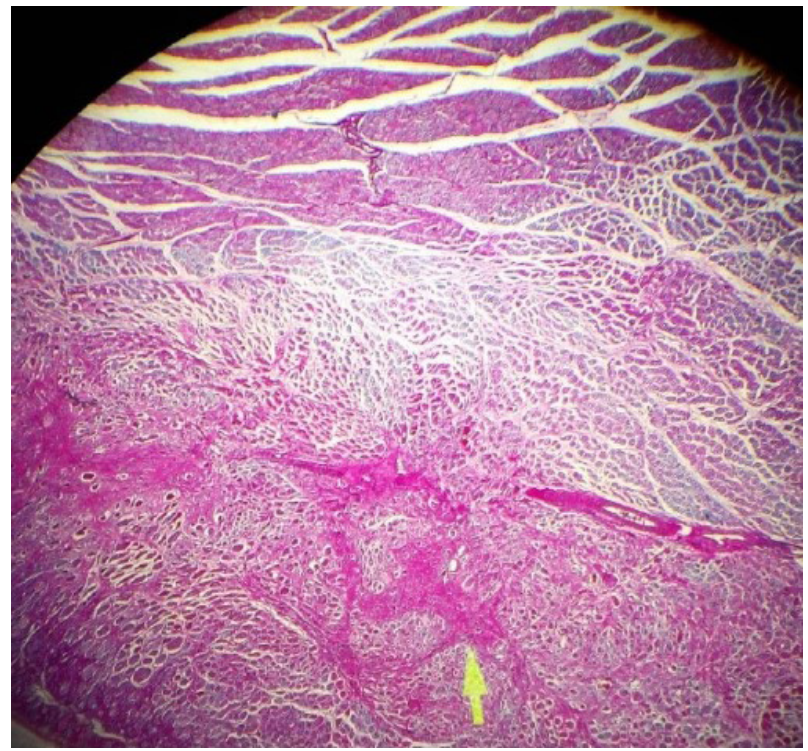

Figure 2. Muscles with moderate fibrotic intensity

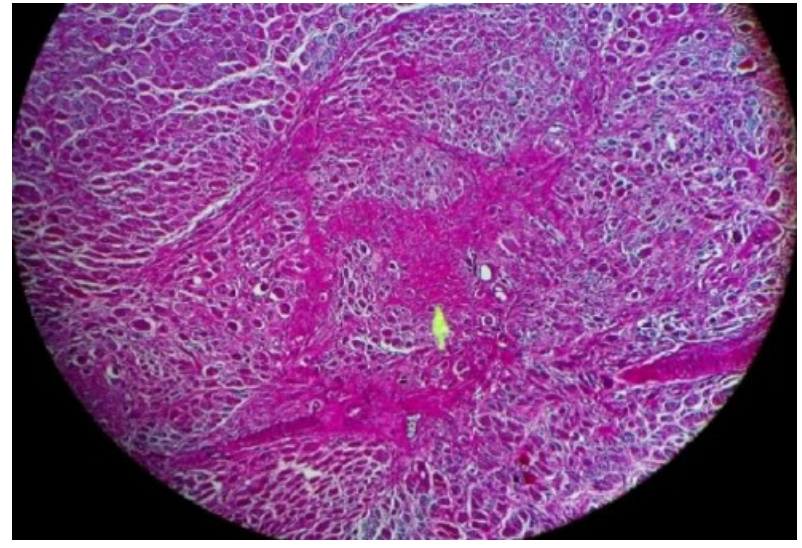

Figure 3. Muscles with strong fibrotic intensity

treatment group was administered with losartan $25 \mathrm{mg} /$ $\mathrm{KgBW}$ using the small orogastric tube.

The research procedure included preparations of muscle injury using drop mass technique, circular cast, inserting losartan (25 mg/KgBW) for three weeks, then harvest of the gastrocnemius muscle, and histopathology Hematoxylin-Eosin and Van Goisson Staining Protocol Goisson examination were done in the Department of Pathology Anatomy. Then, the evaluation of fibrotic intensity and distribution was done by an anatomical pathologist.

Histopathology measurement was done using the Histoscore system. This score is divided into 2 subjects, fibrotic intensity and fibrotic distribution. The range of fibrotic scoring is $0-3$, score 0 if there are no fibrotic tissue (Figure 1 ), score 1 if the fibrotic intensity is weak, score 2 for moderate fibrotic intensity (Figure 2), and score 3 for strong moderate intensity (Figure 3), while fibrotic distribution was divided into 4 groups, with range 1-4. Score 1 
Table 1. Fibrotic intensity, fibrotic distribution, and H-Score in control group

\begin{tabular}{cllll}
\hline \multirow{2}{*}{ Sample } & No & $\begin{array}{l}\text { Fibrotic } \\
\text { Intensity }\end{array}$ & $\begin{array}{l}\text { Fibrotic } \\
\text { Distribution }\end{array}$ & H-Score \\
\cline { 2 - 5 } Group I & 1 & 3 & 2 & 8 \\
& 2 & 3 & 1 & 4 \\
& 3 & 2 & 2 & 6 \\
& 4 & 2 & 2 & 6 \\
& 5 & 3 & 2 & 8 \\
& 6 & 3 & 1 & 4 \\
& 7 & 2 & 2 & 6 \\
& 8 & 3 & 1 & 4 \\
& 9 & 2 & 1 & 3 \\
& 10 & 2 & 2 & 6 \\
\hline Mean & & & & 5.5 \\
\hline
\end{tabular}

Table 2. Fibrotic intensity, fibrotic distribution, and H-Score in Losartan treatment group

\begin{tabular}{cllll}
\hline Sample & No & $\begin{array}{l}\text { Fibrotic } \\
\text { Intensity }\end{array}$ & $\begin{array}{l}\text { Fibrotic } \\
\text { Distribution }\end{array}$ & H-Score \\
\cline { 2 - 5 } Group 2 & 1 & 3 & 1 & 4 \\
& 2 & 3 & 1 & 4 \\
& 3 & 3 & 1 & 4 \\
& 4 & 0 & 0 & 0 \\
& 5 & 0 & 0 & 0 \\
& 6 & 0 & 0 & 0 \\
& 7 & 0 & 0 & 0 \\
& 8 & 0 & 0 & 0 \\
& 9 & 0 & 0 & 0 \\
& 10 & 0 & 0 & 0 \\
\hline Mean & & & & 1.2 \\
\hline
\end{tabular}

if the fibrotic distribution is less than $20 \%$, score 2 if the fibrotic distribution within $20-50 \%$, score 3 if the fibrotic distribution is $51-80 \%$, and score 4 if the fibrotic distribution more than $80 \%$ (Gal et al., 2008).

Later, the results of the special staining of the two groups were compared using the scoring of the $\mathrm{H}$-score system :

\section{H-Score $=($ Fibrotic Instensity+1) $\quad x$ Fibrotic Distribution.}

This score has a range from 2 to 16 . Afterwards, the data collection and statistical analysis were carried out by using Kolmogorov-Smirnov and Mann-Whitney tests with $\mathrm{p}<0.05$ for significant differences.
Table 3. Characteristic of result sample group (control and Losartan treatment group)

\begin{tabular}{ll}
\hline Variable & $\mathbf{N}=\mathbf{2 0}$ \\
\hline Fibrotic Intensity & \\
\hline Mild & $0(0,0 \%)$ \\
Moderate & $5(25.0 \%)$ \\
Strong & $8(40.0 \%)$ \\
None & $7(35.0 \%)$ \\
\hline Fibrotic Distribution & \\
\hline 0 & $7(35.0 \%)$ \\
$<20 \%$ & $7(35.0 \%)$ \\
$20-50 \%$ & $6(30.0 \%)$ \\
$51-80 \%$ & $0(0,0 \%)$ \\
$>80 \%$ & $0(0,0 \%)$ \\
\hline H-Score Fibrotic & \\
\hline Mean \pm STD & $3.3500 \pm 2.833$ \\
Median & 4.000 \\
Range (min-max) & $0.00-8.00$ \\
\hline
\end{tabular}

\section{RESULTS}

Table 1 and 2 showed the results of this study. There was decreasing mean of fibrotic tissue formation in muscle healing after blunt trauma, the mean control group is 5,5 and mean for treatment group is 1,2.

Table 3 below explained the overall characteristic of all fibrotic intensity, fibrotic distribution, and $\mathrm{H}$-score in both groups. From the experiment, it was found that 5 samples $(25.0 \%)$ showed moderate intensity, 8 samples (40.0\%) indicated strong fibrotic intensity, and 7 samples $(35.0 \%)$ did not have fibrotic. The mean for H-Score was $3.3500 \pm 2.833$.

The data was analyzed using Kolmogorov-Smirnov statistical test (Table 4). The result was $p=0.015$ (significant if $\mathrm{p}<0.05$ ). It shows that there were meaningful differences in the proportion of fibrotic intensity and fibrotic distribution variable.

Meanwhile, Mann-Whitney analysis was used to calculate the distribution of $\mathrm{H}$-score, as the data was abnormal. From the formula, as seen in Table 5, it resulted that fibrotic $\mathrm{H}$-score was $\mathrm{p}=0.0001$ (significant if $p<0.05$ ). This, therefore, concluded that there were significant differences in the mean between 2 sample groups. 
Table 4. Kolmogorov Smirnov result

\begin{tabular}{llll}
\hline \multirow{2}{*}{ Variable } & \multicolumn{2}{c}{ Group } & \multirow{2}{*}{ P Value } \\
\cline { 2 - 3 } & Group 1 & Group 2 & \\
\cline { 2 - 3 } & $\mathbf{N}=\mathbf{1 0}$ & $\mathbf{N}=\mathbf{1 0}$ & \\
\hline Fibrotic Intensity & & & \\
\hline Mild & $0(0.0 \%)$ & $0(0.0 \%)$ & \\
Moderate & $5(50.0 \%)$ & $0(0.0 \%)$ & \\
Strong & $5(50.0 \%)$ & $3(30.0 \%)$ & \\
None & $0(0.0 \%)$ & $7(70.0 \%)$ & \\
\hline Fibrotic Distribution & & & \\
\hline 0 & $0(0.0 \%)$ & $7(70.0 \%)$ & \\
$<20 \%$ & $4(40.0 \%)$ & $3(30.0 \%)$ & \\
$20-50 \%$ & $6(60.0 \%)$ & $0(0.0 \%)$ & \\
$51-80 \%$ & $0(0.0 \%)$ & $0(0.0 \%)$ & \\
$>80 \%$ & $0(0.0 \%)$ & $0(0.0 \%)$ & \\
\hline $\begin{array}{l}\text { Group 1: Control Group; Group 2: Losartan Treatment Group } \\
\text { Significant value if p }<0.05 . \text { Marker** showed p-value }<0.05,\end{array}$ &
\end{tabular}

Table 5. Mann Whitney H-Score Result

\begin{tabular}{|c|c|c|c|}
\hline \multirow{3}{*}{ Variable } & \multicolumn{2}{|l|}{ Group } & \multirow{3}{*}{ P Value } \\
\hline & Group 1 & Group 2 & \\
\hline & $\mathrm{N}=10$ & $\mathrm{~N}=10$ & \\
\hline H-Score Fibrosis & & & $0.0001 * *$ \\
\hline Mean \pm STD & $5.500 \pm 1.7159$ & $1.200 \pm 1.932$ & \\
\hline Median & 6.000 & 0.000 & \\
\hline Range (min-max) & $3.00-8.00$ & $0.00-4.00$ & \\
\hline
\end{tabular}

\section{DISCUSSION}

Investigation anti-fibrotic properties of angiotensin receptor type I blocker (ARB) in muscle healing from previous studies showing effects on myocardial and smooth muscle tissue injury. The role of angiotensin II in muscle fibrotic after injury is well documented in the cardiac literature, where angiotensin II antagonists with ARBs are noted to significantly improve cardiac contractility and cardiac output (Gremmler et al., 2000). The histologic analysis also suggests that heart repair mechanisms are associated with decreased fibrosis and enhanced regeneration. The effects of ARB on skeletal muscle healing, however, remain largely unstudied.

The fibrotic formation is the main problem to be solved in the muscle healing process, with the main intention is to maximize muscle's functional healing. This suboptimal healing makes muscles weaker and less flexible, and it also increases the chance of re-rupture. As we know, TGF- $\beta$ cytokines is a regulator for fibrotic tissue production, which transform myoblast into myofibroblast, which is then differentiated to become fibrotic tissue in chronic muscle pathology (Meinen et al., 2012). Although TGF- $\beta$ blocking substances have already been found and known for its effectiveness in fibrotic tissue problems, such as Decorin, Suramin, and Relaxin (Mann et al., 2011; Terada et al., 2013), yet these drugs are not yet openly distributed in Indonesia, which makes it quite expensive and mostly requires injection use. Losartan is thus chosen for its ability to decrease TGF- $\beta$ cytokine and its well-availability in all age group (Cohn et al., 2007). We hypothesized, that Losartan would improve the muscle healing process in acute muscle injury by decreasing fibrotic tissue.

Losartan tablet is an ARB drug which is commonly used for hypertension. Receptor angiotensin Type 1 regulates Thrombospondin (TSP 1) where the TSP 1 is the controller of TGF- $\beta$ production. Losartan inhibits the activity of 


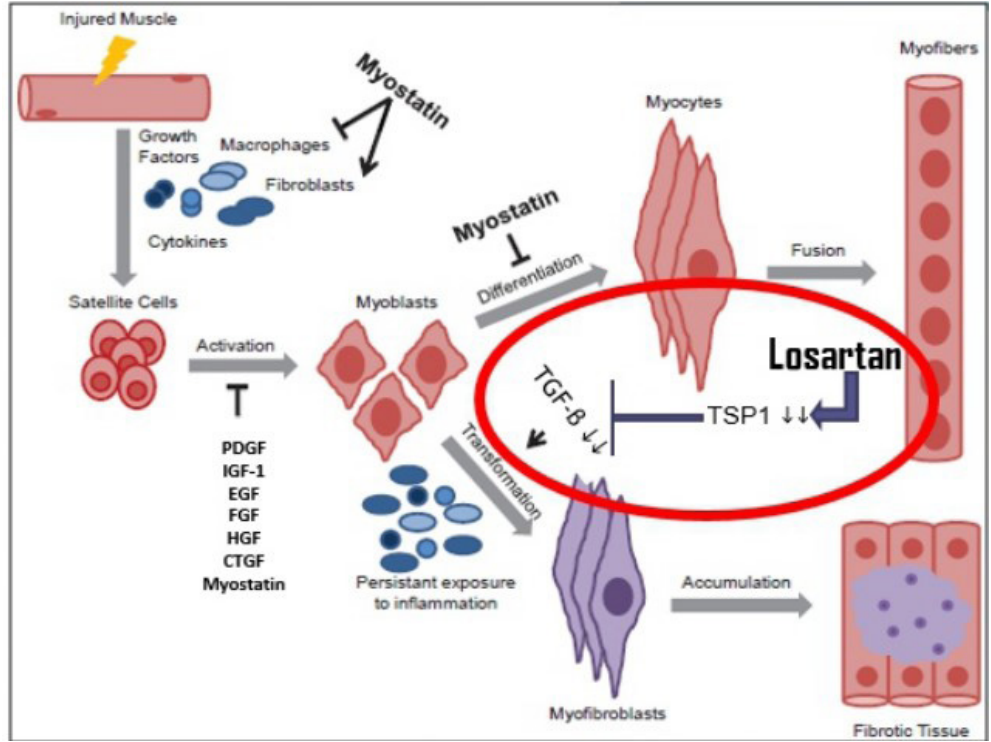

Figure 4. Losartan effect to the acute muscles injury

angiotensin, thus decrease the TGF- $\beta$ cytokines production then decreasing of fibrotic tissue formation (Figure 4). The measurement of the fibrotic intensity and fibrotic distribution, obtained in the experiment, were done by anatomy pathologist before converted to the $\mathrm{H}$-score.

The statistic result for H-score was $\mathrm{p}=0.0001$ (significant if $\mathrm{p}<0.05$ ), which showed that there was a significant difference between the H-Score of the control group and the H-score of the administered group. As a finding of this research (see table 4), Losartan tablets gives significant influence in the fibrotic formation on acute muscle injury grade 1. It is similar to Meinen research which had a conclusion that Losartan could decrease fibrotic tissue but in chronic muscle pathology (Meinen et al., 2012).

This finding may clinically fascinate anti-fibrotic therapy and potentially developed so far for healthy individuals with an acute skeletal muscle injury.

Clinical trials on losartan as an anti-fibrotic agent to promote optimal muscle healing is not yet clear, therefore it is important to pay attention to its potential disadvantages effects of angiotensin II receptor antagonist. The adverse effect profile of ARB is very minimal compared to other antihypertensive drugs; dose-related side effects are hypotension, whereas non-dose related adverse include headaches, dizziness, weakness, and fatigue (Aronson, 2015).

\section{CONCLUSION}

In summary, we have demonstrated in rabbits model that losartan treatment regimen can improve overall skeletal muscle healing after a muscle contusion injury by inhibiting the development of fibrosis. Losartan treatment accelerated the functional recovery of the muscle after injury and, more importantly, this treatment could be readily applied clinically.

\section{ETHICAL CLEARANCE}

This research was approved by Ethical Committee with letter no. LB04.01/A05EC/049/11/2016.

\section{GRANT AND FUNDING}

There are no financing assistances for this research, all expenses incurred by researcher.

\section{CONFLICT OF INTEREST}

The authors declare that they have no conflict of interest.

\section{REFERENCES}

Aronson, J. K. (2015). Meyler's side effects of drugs: the international encyclopedia of adverse drug reactions and interactions: Elsevier.

Cohn, R. D., van Erp, C., Habashi, J. P., Soleimani, A. A., Klein, E. C., Lisi, M. T., Loeys, B. L. (2007). Angiotensin II type 1 receptor blockade attenuates TGF- $\beta$-induced failure of muscle regeneration in multiple myopathic states. Nature medicine, 13(2), 204.

Ekstrand, J., Askling, C., Magnusson, H., \& Mithoefer, K. (2013). Return to play after thigh muscle injury in elite football players: implementation and validation of the Munich muscle injury classification. Br J Sports Med, bjsports-2012-092092. 
Gal, P., Kilik, R., Mokry, M., Vidinsky, B., Vasilenko, T., Mozes, S., Lenhardt, L. (2008). Simple method of open skin wound healing model in corticosteroid-treated and diabetic rats: standardization of semi-quantitative and quantitative histological assessments. Vet Med, 53(12), 652-659.

Gremmler, B., Kunert, M., Schleiting, H., \& Ulbricht, L. (2000). Improvement of cardiac output in patients with severe heart failure by use of ACE-inhibitors combined with the AT1-antagonist eprosartan. European journal of heart failure, 2(2), 183-187.

Mann, C. J., Perdiguero, E., Kharraz, Y., Aguilar, S., Pessina, P., Serrano, A. L., \& Muñoz-Cánoves, P. (2011). Aberrant repair and fibrosis development in skeletal muscle. Skeletal muscle, 1(1), 21.

Medicine, A. C. o. S. (2012). ACSM's resource manual for guidelines for exercise testing and prescription: Lippincott Williams \& Wilkins.

Meinen, S., Lin, S., \& Ruegg, M. A. (2012). Angiotensin II type 1 receptor antagonists alleviate muscle pathology in the mouse model for laminin- $\alpha 2$-deficient congenital muscular dystrophy (MDC1A). Skeletal muscle, 2(1), 18.

Nugroho, B. S. (2016). Tingkat Pengetahuan Atlet Tentang Cedera Ankle dan Terapi Latihan di Persatuan Sepak Bola Telaga Utama. Fakultas Ilmu Keolahragaan.

Pessina, P., Cabrera, D., Morales, M. G., Riquelme, C. A., Gutiérrez, J., Serrano, A. L., Muñoz-Cánoves, P. (2014). Novel and optimized strategies for inducing fibrosis in vivo: focus on Duchenne Muscular Dystrophy. Skeletal muscle, 4(1), 7.

Terada, S., Ota, S., Kobayashi, M., Kobayashi, T., Mifune, Y., Takayama, K., Otsuka, T. (2013). Use of an antifibrotic agent improves the effect of platelet-rich plasma on muscle healing after injury. JBJS, 95(11), 980-988.

Trojian, T. H. (2013). Muscle contusion (thigh). Clinics in sports medicine, 32(2), 317-324.

Yang, J., Xue, Q., Miao, L., \& Cai, L. (2011). Pulmonary fibrosis: a possible diabetic complication. Diabetes/ metabolism research and reviews, 27(4), 311-317. 